\title{
Vraaggerichte geestelijke zorg
}

\section{Een antwoord op religieus pluralisme en secularisatie ${ }^{\mathrm{I}}$}

\author{
Wendy Cadge*
}

\begin{abstract}
Summary
American society is increasingly characterized by secularization and religious pluralism. Therefore, citizens no longer turn to the predecessors of the traditional churches. Spiritual caregivers can respond to this development by working in a more demand-oriented way. Three pilot studies show how spiritual caregivers can respond to the new challenges. These cannot be addressed purely on an individual level, but also require an institutional approach.
\end{abstract}

\section{Inleiding}

De religieuze demografie verschuift in de Verenigde Staten - langzamer dan in Nederland - maar die verandering gaat nog steeds door. Ongeveer een kwart van de mensen in de Verenigde Staten is religieus niet gelieerd aan een bepaald kerkgenootschap en van de mensen onder de 30 is dat al een derde. Ook het aantal inschrijvingen op theologische hogescholen daalt. Intussen is meer dan een kwart van de theologische hogescholen de afgelopen jaren begonnen met trainingsprogramma's voor geestelijk verzorgers - met een breed scala aan onderwerpen die niet standaard zijn in de Verenigde Staten. Veel van mijn collega's en ikzelf ook denken dat onderwijs voor pastoraat en spirituele zorg op dit moment een van de weinige groeiende vormen van theologisch onderwijs in de Verenigde Staten is.

Met veel belangstelling volg ik de ontwikkelingen in Europa en zeker ook in Nederland. Het recente onderzoek van Liefbroer (2020) gaat over het overstijgen van religieuze verschillen tussen geestelijk verzorgers en hun gesprekspartners. Ook andere onderzoekers hebben gekeken naar hoe geestelijk verzorgers dit doen in individuele interacties. Zo blijkt bijvoorbeeld uit de antropologische studie van Frances Norwood naar wat zij de 'ambivalente

* Wendy Cadge is hoogleraar sociologie aan de Brandeis Universiteit in Massachusetts (VS); tevens bekleedt zij daar de Barbara Mandel leerstoel voor Humanistic Social Sciences. 
geestelijk verzorger' noemt, hoe geestelijk verzorgers in de gezondheidszorg zich bewegen tussen discoursen over religie, spiritualiteit en geneeskunde in plaats van tussen verschillende religieuze en spirituele talen en gebruiken in hun dagelijkse werk (Norwood 2006). Daarentegen laat een studie van gevangenispastoraten in het Verenigd Koninkrijk zien hoe geestelijk verzorgers van de Church of England de toegang tot de gevangenis vergemakkelijken voor boeddhistische, moslim- en sikh-geestelijk verzorgers, zodat ze leden van hun tradities kunnen bezoeken. Over hoe geestelijk verzorgers in andere sectoren omgaan met religieuze diversiteit in hun werk is nog maar weinig bekend (Beckford \& Gilliat 1998).

In mijn eigen onderzoek ben ik nagegaan hoe geestelijk verzorgers in de gezondheidszorg de strategieën van neutralisatie en code-switching gebruiken om te werken met patiënten met een andere religieuze achtergrond dan die van henzelf (Cadge \& Sigalow 2013). Geestelijk verzorgers proberen religieuze verschillen meestal te neutraliseren door te benadrukken wat ze gemeen hebben. Zij neutraliseren of overbruggen religieuze verschillen verder door de nadruk te leggen op menselijke - die ze in toenemende mate spirituele noemen - universalia waarvan zij geloven dat ze alle mensen verbinden. Naast het neutraliseren van religieuze verschillen, schakelen de geestelijk verzorgers ook om tussen religieuze talen, symbolen en soms rituelen in hun werk met patiënten en gezinnen (Blom \& Gumperz 1972; Goffman 1979; 1981). De meer conventionele manieren waarop geestelijk verzorgers van code wisselen, komen vooral naar voren in hun beschrijvingen van het gebed met patiënten.

Op dit moment worstelen mensen in de Verenigde Staten - net als overal ter wereld - met de pandemie, met politieke polarisatie en economische uitdagingen naast de gebruikelijke strijd om mens te zijn bij existentiële problemen als ziekte, lijden, dood. Terwijl de generatie van mijn grootouders in de Verenigde Staten zich tot hun plaatselijke religieuze leiders wendde, hebben mensen van mijn generatie en degenen die iets jonger zijn dan ik dergelijke leiders niet, dus waar moeten ze heen? Collega's die onlangs het 'Sacred Design Lab' hebben gelanceerd, een innovatief samenwerkingsverband van onderzoekers en professionals op gebied van rituelen, zien hoe millennials zich tot yogadocenten, 'potluck-dinners (gezamenlijke maaltijden waarbij ieder zelfbereid eten meebrengt), 'soul cycle' (fitness, gericht op een mentale boost) en andere voorzieningen en diensten wenden om betekenis, doel en gemeenschap te vinden. Ze schreven een paar jaar geleden een rapport hierover genaamd 'How We Gather'. 
Wat betekenen al deze ontwikkelingen voor het pastoraat en geestelijke zorg? Ik denk dat als mensen zich wenden tot iemand met een theologische opleiding, het steeds waarschijnlijker wordt dat die persoon een 'chaplain' of geestelijk verzorger is in plaats van een plaatselijke priester, predikant, rabbijn of imam. ${ }^{2}$ In de Verenigde Staten kunnen ze die geestelijk verzorgers ontmoeten op een spoedafdeling van een ziekenhuis, in het leger, in een rampenteam van het Rode Kruis of op een hogeschool of universiteit.

\section{Vraaggerichte geestelijke zorg?}

Wat betekent het om spirituele zorg te verrichten in deze veranderende demografische contexten? Ik denk dat we moeten nadenken over een vraaggericht model. En wat bedoel ik daarmee? Ik wil daarmee zeggen dat we bij onszelf en voor het beroep van geestelijk verzorger ons moeten afvragen waarvoor de diensten van geestelijk verzorgers nodig zijn. Te veel gesprekken in de Verenigde Staten over spirituele zorg zijn gericht op de voorziening - hoe aalmoezeniers het beste kunnen worden opgeleid, gecertificeerd, ingezet, enzovoort. Dit zijn belangrijke aspecten, maar zij komen op de tweede plaats. Op de eerste plaats moet de vraag komen waarvoor de diensten van geestelijk verzorgers nodig zijn.

Laten we vanuit dit standpunt enkele uitdagende vragen stellen: Hoe zou het werk van de geestelijk verzorger veranderen als het volledig gebaseerd was op de vraag naar spirituele zorg? Wat zijn de activiteiten van geestelijk verzorgers die niet gebaseerd zijn op een duidelijke vraag en welke van hun activiteiten hebben mogelijk weinig resultaat of impact? Als de middelen (inclusief tijd en energie) onbeperkt waren, waar ligt dan de vraag naar spirituele zorg die we zouden kunnen aanpakken? Waar zien we de vraag naar geestelijke verzorging zich voordoen en, als we opnieuw zouden moeten beginnen, waar (d.w.z. in welke omgevingen en instellingen) zouden geestelijk verzorgers dan het best ingezet kunnen worden?

Traditioneel wordt spirituele zorg verleend via instellingen zoals ziekenhuizen, verpleeginstellingen, universiteiten en hogescholen en gevangenissen. In deze omgevingen bezochten geestelijk verzorgers mensen, organiseerden ze programma's en hielden ze diensten, naast andere activiteiten. Sommige van hun activiteiten zijn veranderd, maar ook worden veel ervan uit gewoonte of institutionele routine herhaald. Vraaggerichte spirituele zorg vereist dat we zoeken en benoemen waar de vraag is. Het vraagt ook dat we stoppen met 
het werk waar er geen vraag is, en dat we dus alleen werk doen daar waar een aantoonbare vraag ligt.

Een vraag naar geestelijke verzorging omvat vaak een vraag naar de vaardigheden van diep luisteren, presentie, gemeenschapsopbouw, een geïmproviseerd ritueel. Hoewel geestelijk verzorgers dit werk doen, is dit etiket niet goed te gebruiken voor sommige mensen en instellingen. Het zich presenteren als geestelijk verzorger opent vaker deuren in het leger, de gezondheidszorg en instellingen die al lang geestelijk verzorgers hebben gehad. In andere omgevingen, zoals technologiebedrijven, onder millennials, en in minder traditioneel religieuze milieus worden de geestelijk verzorgers als te christelijk gezien (vooral ook door hun taalgebruik) en daardoor wordt toegang tot deze instellingen en groeperingen afgesloten.

We lanceerden het 'Chaplaincy Innovation Lab' aan de Brandeis University bijna twee jaar geleden om praktische innovatie van vraaggerichte geestelijke verzorging tot stand te brengen en waar mogelijk te stimuleren. Ik ga nu in op drie vraag-gestuurde projecten in verschillende stadia van ontwikkeling, om vervolgens iets aan te geven over religieuze verschillen in deze projecten en het vraag-gestuurde karakter ervan.

\section{Geestelijke zorg voor geïsoleerde ouderen}

Als eerste wil ik het proefproject noemen dat gericht is op het bieden van spirituele zorg aan geïsoleerde ouderen. We weten dat eenzaamheid en sociaal isolement veel voorkomen bij ouderen, waarbij een derde van de verpleeghuisbewoners zelden bezoek krijgt (Tsai et al. 2010). De frequentie van eenzaamheid bij ouderen is zorgwekkend vanwege de correlaties tussen eenzaamheid en een slechte mentale en fysieke gezondheid (Luanaigh \& Lawlor 2008).

We werken samen met een verpleeginstelling, genaamd 'Hebrew Senior Life', die contact onderhoudt met veel ouderen die nog zelfstandig wonen. Het idee, vóór COVID, was om te focussen op ouderen die bezocht worden door medische assistenten; zij zijn immers de basiszorgverleners die periodiek contact met hen onderhouden. We hebben deze medische assistenten getraind om een basisscreening uit te voeren om sociaal isolement te beoordelen en om geïsoleerde cliënten door te verwijzen naar een geestelijk verzorger die een reeks bezoeken zou afleggen als ze daartoe welkom was. Tijdens de COVID- 
crisis waren persoonlijke contacten niet meer mogelijk. Daardoor ontstonden problemen met de verwijzing door de medische assistenten, omdat die verwijzing nu op afstand moest gebeuren. De geestelijk verzorger belde daarom zelf 29 bewoners die thuiszorg ontvingen; 25 van hen wilden deelnemen. De geestelijk verzorger belde deze 25 deelnemers gedurende 20 weken, met een gemiddeld aantal gesprekken met elke bewoner van 10,7. Het gemiddelde gesprek duurde 30,5 minuten.

De deelnemers brachten zowel voor als tijdens COVID vooral de negatieve effecten van isolatie naar voren. Vele ouderen zien enkel de assistenten, met wie ze al dan niet een goede band hebben. Als ze geluk hebben, krijgen ze op afstand familiebezoek. Activiteiten om eenzaamheid te compenseren, zoals lichaamsbeweging of ontspanning, kunnen bijzonder moeilijk zijn voor senioren. Vaak hebben ze een beperkte mobiliteit. Geregeld hebben ze problemen met de technologische hulpmiddelen om veilig online contact mogelijk te maken, wat de isolatie nog heeft versterkt. Voeg daarbij dat zij in deze Covidperiode bezwaar hadden tegen persoonlijk contact met de geestelijk verzorger omdat zij vreesden voor de gezondheid en veiligheid van gezinsleden. Veel deelnemers spraken hun dankbaarheid uit voor het feit dat ze niet ziek waren of niet in het ziekenhuis waren opgenomen. Tegelijk werd het gebrek aan contact nadrukkelijk naar voren gebracht. Dan werd niet alleen het persoonlijk verlies genoemd maar ook werd erop gewezen dat hun verdriet en angst werden versterkt door het lezen van de namen van vrienden in de overlijdensberichten.

\section{Geestelijke verzorging aan studenten}

Ten tweede hebben we de afgelopen jaren geprobeerd om het werk van geestelijk verzorgers aan Amerikaanse hogescholen en universiteiten beter te begrijpen. We probeerden vast te stellen of het contact met geestelijk verzorgers voor de studenten enig effect heeft op hun korte of lange termijn welzijn - waarmee we dus naast de vraaggerichtheid ook de impact van deze zorg wilden nagaan. Amerikaanse universiteitsstudenten kampten, zelfs vóór COVID, met een toenemende mate van angst en depressie. En dat terwijl veel universiteiten moeite hebben om hun centra voor geestelijke gezondheidszorg bemand te houden en om in de behoeften van studenten te voorzien. Sommige hebben groepsondersteuning geïntroduceerd omdat ze niet de middelen hebben om elke student die daarom vraagt, individuele therapie te bieden. 
Twee jaar geleden hebben we een pilotstudie uitgevoerd op één campus om het effect van de inzet van geestelijk verzorgers op het welzijn van studenten na te gaan. Iets meer dan 1000 studenten vulden een enquête in. Bijna de helft van de respondenten, variërend naar religieuze traditie en etnische herkomst, meldde contact met een geestelijk verzorger. Respondenten die contact hadden met een geestelijk verzorger gaven eerder aan dat ze spiritualiteit in het dagelijks leven hadden geïntegreerd, dat ze zich gesteund voelden bij het worstelen met de grote levensvragen en dat ze spirituele groei hadden ervaren. Aan de andere kant scoorden ze niet hoger op veerkracht en stressbeheersing dan studenten die geen contact hadden met een geestelijk verzorger.

Vervolgens hebben we deze studie uitgebreid. Het oogmerk was om preventieve zorg te versterken, teneinde het aantal studenten dat in de knel komt te verminderen. We hebben groepswerk georganiseerd op twee hogescholen in Massachusetts voor zowel studenten als afgestudeerden. Dat onderzoek loopt nog. Elke groep komt gedurende vijf weken bijeen en wordt mede gefaciliteerd door een therapeut van het gezondheidscentrum en een geestelijk verzorger verbonden aan de universiteit. Deze groepen hebben 10 of 12 deelnemers en zijn erop gericht om verbondenheid, welzijn en veerkracht te bevorderen.

Alhoewel we nog geen definitieve resultaten hebben, maakt dit project nu al twee dingen duidelijk. Ten eerste toont de studie de waarde aan van de samenwerking tussen geestelijk verzorgers en andere professionals. Ten tweede wordt zichtbaar hoe er een duidelijke vraag is van deze andere disciplines naar de vaardigheden en inzet van geestelijk verzorgers. Het kan zijn dat ze een deel van hun traditionele werk moeten stoppen of aanpassen om op deze vraag in te gaan. Misschien is dat ongemakkelijk, maar we denken dat het nodig is om hun werk verder te ontwikkelen.

\section{Hoe begrijpen leidinggevenden in de gezondheidszorg geestelijke zorg?}

Het laatste voorbeeld gaat niet zozeer over het bepalen waar vraag is naar geestelijke verzorging, maar over het proberen te begrijpen hoe degenen die beslissingen nemen over de middelen van geestelijke verzorging, de vraag zien. Het gaat dus niet om de individuele maar om de institutionele vraag. Dit project 'Spiritual Care in Healthcare: Identifying Decision Makers' Perspectives' hebben we net afgerond. Hoe denken besluitvormers in de gezondheidszorg over geestelijke verzorging en welke waarde hechten ze aan de inzet van geestelijk 
verzorgers? Na enkele korte casestudies hebben we 25 semi-gestructureerde interviews afgenomen, 11 met managers in de gezondheidszorg op directie- of bestuursniveau en 14 met managers van geestelijk verzorgers. Samen vertegenwoordigen ze 18 ziekenhuizen en 9 gezondheidssystemen.

We ontdekten dat beide groepen leidinggevenden in de gezondheidszorg de waarde van geestelijke verzorging zien in termen van ondersteuning bij tragische situaties, maar ook in tijden van organisatieveranderingen. De ondervraagde leidinggevenden beschouwen geestelijke verzorging als betrouwbare dienstverlening die kan inspelen op behoeften van patiënten en personeel en op die manier bijdraagt aan de kwaliteit van zorg. De waarde van de geestelijke verzorging zit onder meer in de competentieontwikkeling door deelname aan de klinische pastorale training en door de ruime ervaring in het opereren binnen een complexe omgeving.

Uit het onderzoek kwamen nog enkele andere interessante bevindingen naar voren. De meeste geïnterviewde leidinggevenden uit beide groepen beschouwen geestelijke verzorging als representant en symbooldrager voor de missie van hun ziekenhuizen; deze missie bevat bepaalde waarden die door geestelijk verzorgers in hun werk naar voren worden gebracht. Tegelijkertijd stelden we vast dat bij een aantal leidinggevenden het kennisniveau van het dagelijkse werk van geestelijk verzorgers beperkt is.

Voor de financiering van geestelijke verzorging worden argumenten aangevoerd gebaseerd op de bijdrage die geestelijk verzorgers leveren aan de bredere missie, de waarden en programma's van de instelling - maar dat geldt alleen voor de leidinggevenden met een zeker inzicht in het werk van geestelijk verzorgers. Wat de formatie van de geestelijke verzorging betreft, lieten de interviews zien dat er aanzienlijke verschillen zijn in de manier waarop de formatie van geestelijke verzorging wordt geregeld en hoe ze geïntegreerd wordt in de ziekenhuizen waar ze aan verbonden is. Ten slotte merkten we op dat veel instellingen wel gegevens verzamelen over het werk van geestelijk verzorgers, maar dat slechts weinig organisaties zich erop baseren bij het nemen van beslissingen over de formatie van geestelijke verzorging. Beslissingen lijken eerder gebaseerd te worden op de budgettaire situatie.

Vanuit deze bevindingen zijn er verschillende gevolgtrekkingen te maken voor zowel de leidinggevenden op directie-of bestuursniveau als de leidinggevenden van geestelijk verzorgers. Voor wat betreft de leidinggevenden op directie- of bestuursniveau gaat het om de volgende zaken: 
- Momenteel zijn het nog te vaak financiële gegevens waarop leidinggevenden hun besluiten inzake de formatie van geestelijke verzorging lijken te baseren en te weinig op informatie over de inzet van geestelijke verzorging en de impact daarvan.

- Veel managers op directie- of bestuursniveau hebben een beperkt begrip van de diensten die geestelijk verzorgers verlenen. Geestelijk verzorgers moeten effectieve manieren vinden om deze managers voor te lichten over wat ze doen. We willen geestelijk verzorgers stimuleren om leidinggevenden te vragen welke informatie ze nodig hebben en hoe ze de communicatie kunnen verbeteren.

- Leidinggevenden in de gezondheidszorg op bestuurs- of directieniveau kunnen gebruik maken van de kennis die leidinggevenden van geestelijk verzorgers hebben om beleid inzake geestelijke verzorging vorm te geven.

Voor wat betreft leidinggevenden van teams geestelijke verzorging:

- Leidinggevenden hebben een beperkt inzicht in de activiteiten van geestelijk verzorgers om ondersteuning te bieden bij crises.

- Leidinggevenden hebben eveneens beperkte kennis van de ondersteuning aan het personeel door geestelijk verzorgers.

\section{Religieus pluralisme en secularisatie- individuele en institutionele benadering}

In deze drie voorbeelden komt de vraaggerichte spirituele zorg telkens op een andere wijze naar voren. ${ }^{3}$ Als we deze aanpak toepassen, moeten we ook nadenken over hoe geestelijk verzorgers religieuze en andere verschillen niet alleen op individueel niveau kunnen overbruggen, maar ook op institutioneel niveau. Twee van de besproken pilotstudies waaraan we werken, die van geïsoleerde ouderen en studenten (ook al zijn van de laatste studie nog geen definitieve resultaten bekend) wijzen in een bepaalde richting, namelijk dat de gesignaleerde vragen bundeling van krachten tussen verschillende disciplines en op het niveau van de organisatie vergen. Ze bevestigen ook de noodzaak van onderzoek, namelijk over interventies en over het meten van de effectiviteit van het werk. Een op onderzoeksresultaten gerichte benadering van geestelijke verzorging ligt aan de basis van de vraaggerichte focus; deze benadering verschilt van de manier waarop de meeste geestelijk verzorgers zijn opgeleid. Ze vereisen dus ook om na te denken over de inrichting van de opleiding, zodat geestelijk verzorgers beter toegerust zijn om zorg te 
verlenen die inspeelt op de vragen van cliënten. Wat betreft de nascholing: in de praktijk zal het beschikbaar stellen van supervisie aan geestelijk verzorgers door leidinggevenden helpen om uitdagingen vanuit de context van religieus pluralisme en secularisatie te identificeren en aan te pakken. Alleen op die manier kunnen we een oplossing vinden voor de vragen aan de aanbodzijde die zo veel van het gesprek in de Verenigde Staten blijven domineren.

\section{Noten}

1 Vertaald en bewerkt door de redactie van dit nummer.

2 Elders in dit nummer gaat Berghuijs op de Nederlandse situatie in (n.v.d.r.)

3 Tijdens de discussie op het symposium verduidelijkte Cadge dat vraagsturing niet betekent zitten wachten op een oproep om begeleiding. Geestelijk verzorgers zullen proactief het contact met de doelgroep dienen op te zoeken en te exploreren welke noden er liggen.

\section{Literatuur}

Beckford, James \& Sophie Gilliat (1998),

Religion in Prison: Equal Rites in a Multi-Faith Society, New York: Cambridge University Press.

Blom, Jan-Petter \& John J. Gumperz (1972),

Social Meaning in Linguistic Structures: Code Switching in Northern Norway, in: Gumperz, J. J. \& D. Hymes (eds), Directions in Sociolinguistics, New York: Holt, Rinehart and Winston.

Cadge, Wendy \& Emily Sigalow (2013,

Negotiating Religious Differences: The Strategies of Interfaith Chaplains in Healthcare, in: Journal for the Scientific Study of Religion, 52 (1),146-58.

Goffman, Erving (1979),

Footing, in: Semiotica, 25, 1-29.

Goffman, Erving (1981),

Forms of Talk, Philadelphia: University of Pennsylvania Press.

Liefbroer, A.I. (2020),

Interfaith spiritual care, PhD thesis, Vrije Universiteit Amsterdam.

Norwood, Frances (2006),

The Ambivalent Chaplain: Negotiating Structural and Ideological Difference on the Margins of Modern-Day Hospital Medicine, in: Medical Anthropology, 25 (1),1-29. 